\title{
Two dose adjustment programs in high-dose methotrexate treatment for pediatric acute lymphoblastic leukemia
}

\author{
Yaqing Shen ${ }^{1}$, Zhujun Wang ${ }^{2}$, Xiaoyan $\mathrm{Wu}^{3}$, Kun $\mathrm{Li}^{3}$, Zhongjian Wang ${ }^{3}$, Wenfu Xu${ }^{1}$, Fen \\ Zhou $^{3}$, and Runming Jin $^{1}$ \\ ${ }^{1}$ Department of Pediatrics, Union Hospital,Tongji Medical College,Huazhong University of \\ Science and Technology,Wuhan,Hubei,China \\ ${ }^{2}$ Union Hospital, Tongji Medical College, Huazhong University of Science and Technology \\ ${ }^{3}$ Union Hospital, Tongji Medical College, Huazhong University of Science and Technology
}

November 16, 2020

\begin{abstract}
Background: Methotrexate is safely administered to most patients but can also cause severe toxicities. It is necessary to individualize methotrexate dose to maintain suf-ficient exposure while minimizing toxicities. Procedure: We enrolled 1174 cycles of high-dose methotrexate chemotherapy from 294 patients treated following the CCCG-ALL-2015 protocol and explored risk fac-tors of toxicities, methotrexate clearance delay and relapse. We compared those who received a fixed-dose reduction (Program 1) with those who were dose-adjusted by added methotrexate concentration test at 16h (Program 2) after methotrexate clear-ance delay existed the last cycle. Results: Female, IR/HR group, BSA $<0.69 \mathrm{~m} 2$ and C44h[?]1.0 $\mu$ mol/L were risk factors of toxicities $(\mathrm{P}<0.05)$. Significant covariates on methotrexate clearance delay were age $>6$ years, male and IR/HR group $(\mathrm{P}<0.01)$. Male, IR/HR and $\mathrm{C} 68 \mathrm{~h}[?] 0.2 \mu \mathrm{mol} / \mathrm{L}$ group patients were at higher risk of relapse $(\mathrm{P}<0.05)$. No significant association was observed between methotrexate dose and relapse-free survival. 405 cycles from 168 patients were dose-adjusted by Program 1 and 118 cycles from 43 patients by Pro-gram 2. Patients who used Program 2 had a higher actual methotrexate infusion dose and infusion rate and was better in keeping $\mathrm{C} 44 \mathrm{~h}$ in our target value $(\mathrm{P}<0.001)$. Ab-normal serum potassium was more frequently in patients using Program2 $(\mathrm{P}<0.001)$, and prolonged myelosuppression was more commonly seen in IR/HR patients with Program2(P=0.003). Conclusions: No significant correlation between methotrexate dose or $\mathrm{C} 44 \mathrm{~h}$ and re-lapse-free survival time was found. Patients who were dose-adjusted by Program 2 received a higher therapeutic dose and better controlled the methotrexate concentra-tion to our target range.
\end{abstract}

\section{Hosted file}

main-document.pdf available at https://authorea.com/users/375977/articles/493148-twodose-adjustment-programs-in-high-dose-methotrexate-treatment-for-pediatric-acutelymphoblastic-leukemia

\section{Hosted file}

TABLE 1 Baseline patient demographics, treatment data and laboratory values based on risk group.pdf available at https://authorea.com/users/375977/articles/493148-two-dose-adjustment-programsin-high-dose-methotrexate-treatment-for-pediatric-acute-lymphoblastic-leukemia

\section{Hosted file}

TABLE 2 Risk factors of toxicity and methotrexate clearance delay at 44h.pdf available at https://authorea.com/users/375977/articles/493148-two-dose-adjustment-programs-in-highdose-methotrexate-treatment-for-pediatric-acute-lymphoblastic-leukemia 


\section{Hosted file}

TABLE 4 Basic demographic information, treatment data and toxicity of two MTX dose adjustment programs. available at https://authorea.com/users/375977/articles/493148-two-dose-adjustment-programsin-high-dose-methotrexate-treatment-for-pediatric-acute-lymphoblastic-leukemia
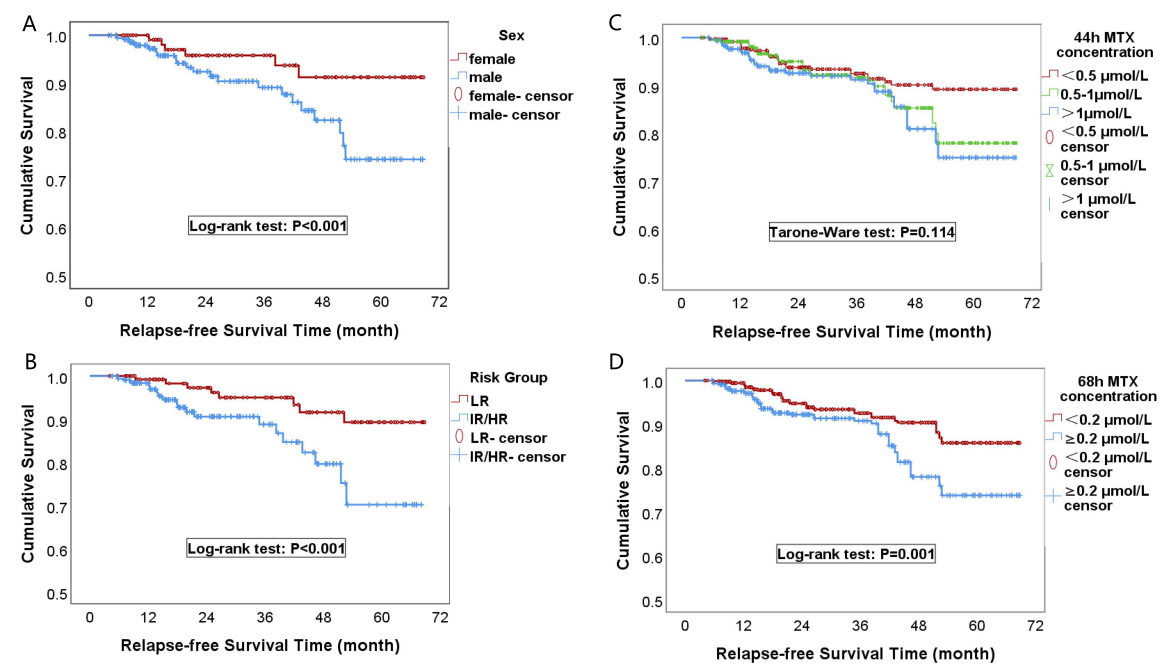


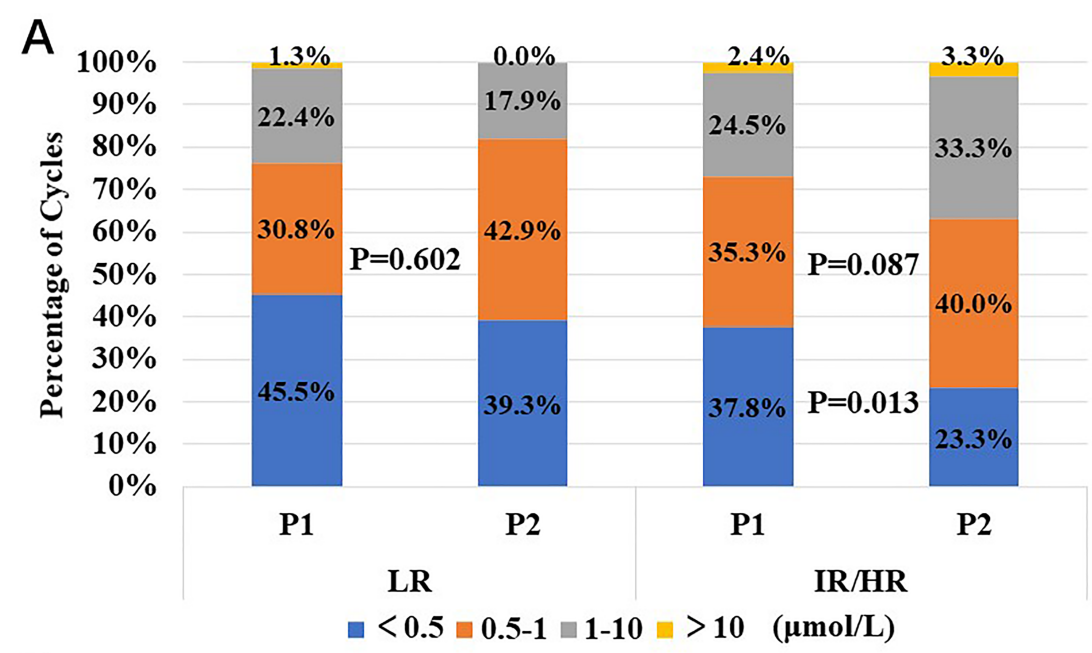

B

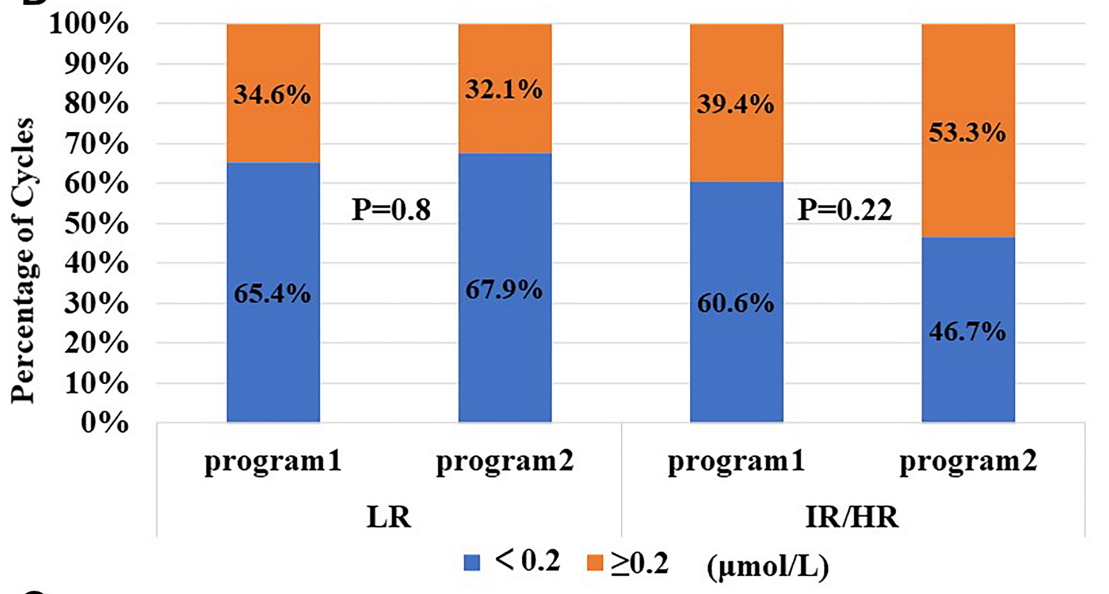

C

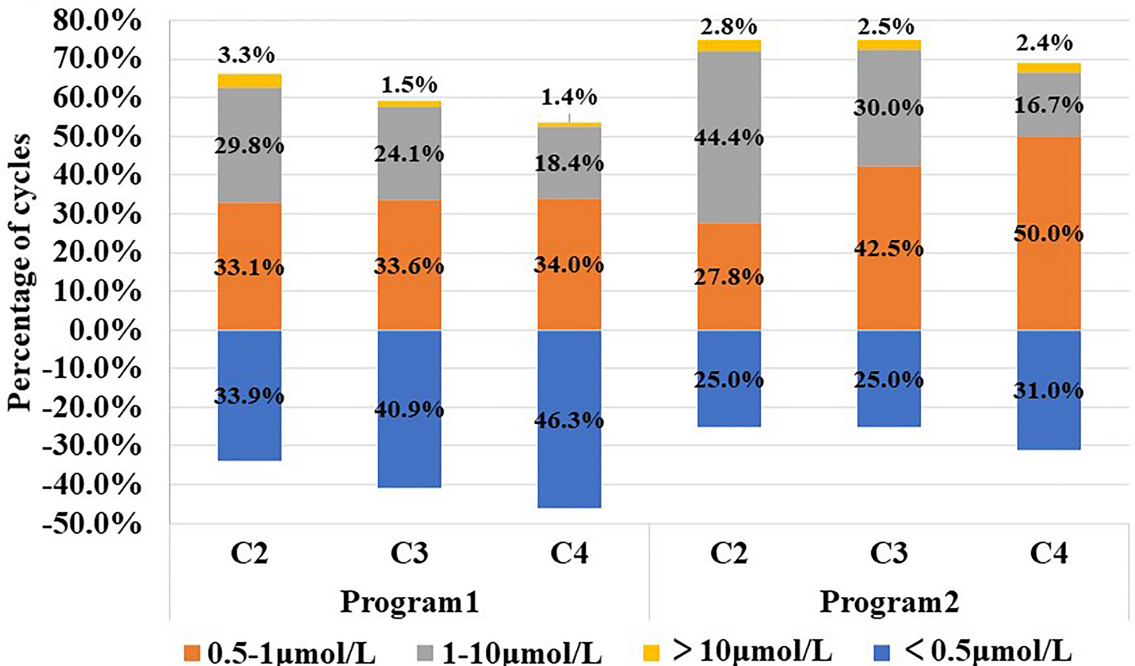

